\title{
Reluctance Network Analysis for Complex Coupled Inductors
}

\author{
Jyrki Penttonen ${ }^{1,2^{*}}$, Muhammad Shafiq ${ }^{2}$, Matti Lehtonen ${ }^{1}$ \\ ${ }^{1}$ Department of Electrical Engineering, Aalto University, Espoo, Finland \\ ${ }^{2}$ Vensum Ltd., Helsinki, Finland \\ Email: *jyrki.penttonen@vensum.com, muhammad.shafiq@vensum.com, matti.lehtonen@aalto.fi
}

How to cite this paper: Penttonen, J., Shafiq, M. and Lehtonen, M. (2017) Reluctance Network Analysis for Complex Coupled Inductors. Journal of Power and Energy Engineering, 5, 1-14.

http://dx.doi.org/10.4236/jpee.2017.51001

Received: December 16, 2016

Accepted: January 7, 2017

Published: January 10, 2017

Copyright () 2017 by authors and Scientific Research Publishing Inc. This work is licensed under the Creative Commons Attribution International License (CC BY 4.0).

http://creativecommons.org/licenses/by/4.0/

\begin{abstract}
The use of reluctance networks has been a conventional practice to analyze transformer structures. Basic transformer structures can be well analyzed by using the magnetic-electric analogues discovered by Heaviside in the $19^{\text {th }}$ century. However, as power transformer structures are getting more complex today, it has been recognized that changing transformer structures cannot be accurately analyzed using the current reluctance network methods. This paper presents a novel method in which the magnetic reluctance network or arbitrary complexity and the surrounding electrical networks can be analyzed as a single network. The method presented provides a straightforward mapping table for systematically linking the electric lumped elements to magnetic circuit elements. The methodology is validated by analyzing several practical transformer structures. The proposed method allows the analysis of coupled inductor of any complexity, linear or non-linear.
\end{abstract}

\section{Keywords}

Power Transformer, Coupled Inductor, Reluctance Networks,

Electromagnetic Modeling

\section{Introduction}

Magnetic circuits are commonly represented by equivalent electrical circuits [1] [2] [3]. In magnetic cores, flux increases when magnetomotive force increases in the same way as current increases by increasing voltage in resistor. This creates analogies between magnetic and electric circuits, where reluctance corresponds to resistance and electromotive force corresponds to magnetomotive force. Also, magnetic fluxes in a reluctance network add up to zero in a same way as currents add up to zero in electrical circuit. Therefore, a magnetic circuit can be modeled 
by first identifying reluctance elements in a transformer structures (limbs, yokes, leakage flux paths) and mapping them as resistances. Winding currents are replaced as voltage sources and the resulted electrical circuit is solved using the traditional circuit analysis methods.

These electric-magnetic analogies constitute a basis to analyze basic transformer structures. However, as transformer structures of today are getting more and more complex, a need has arisen to come up with a more systematic treatment of coupled inductors so that their dynamics could be modeled effectively in situations, which are considered to be challenging. The methodologies presented in transformer literature [4] [5] are for power transformer analysis under symmetrical core. For asymmetric three-phase magnetic cores, the reluctances of individual limbs vary. This method, however, cannot be generalized as it is hard wired to one particular core structure. Analysis methods for complex multi limb transformer structures are presented in [6]-[12], however they are not generic enough for systematic treatment of arbitrary complex coupled inductors.

Most circuit analysis tools, such as Simulation Program with Integrated Circuit Emphasis (SPICE), provide methods to include transformers into transient and steady state analysis [13]. These, however, allow typically transformer to be represented by means of coupling factor. While this suits well for the analysis of a single core multi-winding transformer, it is not suitable for systems including multiple limbs and complex interconnection of the windings.

Power system analysis softwares such as Electro Magnetic Transients Program/ Alternative Transients Program (EMTP/ATP) [14] provide modules to model transformers, but they are also limited to a small set of known transformer types such as: single-phase single-limb and three-phase three-limb.

The motivation of the development of the methodology presented in this paper arose from practical complex transformer design problems, which could not be easily addressed using the methods available today. For example, the magneto-electric circuit in Figure 1 is one practical example that is hard to analyze using methods of the current art. It includes asymmetry via yoke reluctances. Solution to this is obviously possible by writing a system of differential equations

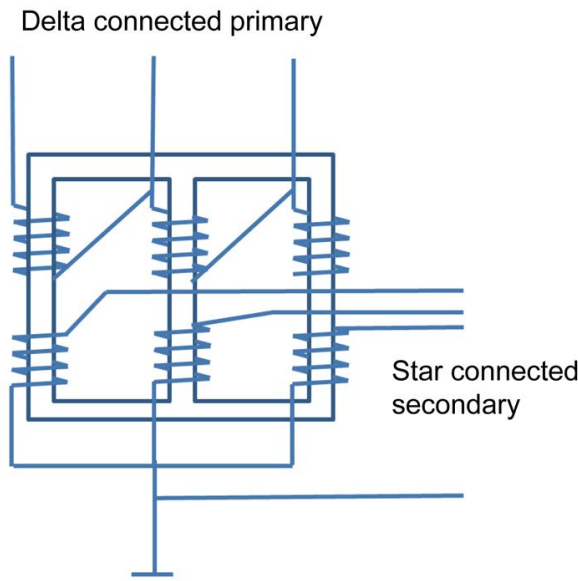

Figure 1. Three-phase three-limb transformer. 
with 6 equations and 6 state variables, which would correspond to magnetic fluxes in the limbs and leakage paths. While this is doable, there is complexity in it, which increases the error possibilities and cannot be generalized to arbitrary transformer structures and the system of differential equations must be formed again for every new case as there is no systematic way to derive them automatically. The analysis method presented in this paper enables to make the analysis automatically for a coupled inductor of any complexity.

In Section 2 mapping rules are introduced in order to transform the equivalent electrical circuits of transformer's windings of a complex coupled inductor into magnetic domain. Section 3 presents the methodology of analyzing the nonlinear magnetic cores. Further in Section 4, the proposed methodology is applied to analyze the performance of two types of practical transformers under different load conditions while conclusion is presented in Section 5.

\section{Mapping Electrical Elements to Magnetic Domain}

This section presents the primary elements of transformers. A methodology is presented, where the electrical circuits surrounding the coupled inductor can be mapped to magnetic domain using defined rules of transformation as described below.

\section{Rule 1: Transformation of voltage source into current source}

A voltage source connected to the windings of an ideal single-phase magnetic core can be seen in Figure 2.

Faraday's law of induction Equation (1) illustrate that the magnetic flux created by the voltage source is an integral of the voltage and can be represented in Laplace space according to Equation (2). Considering the electric-magnetic analogies we can thereby represent voltage source in electrical domain as current source in magnetic domain as shown in Figure 3.

$$
\begin{aligned}
& E[t]=N \phi^{\prime}[t] \\
& \phi=\frac{E}{s N}
\end{aligned}
$$

\section{Rule 2: Transformation of current source into voltage source}

When there is a current source connected to reactor windings, this can be represented in magnetic circuit as a voltage source using the traditional analogy:

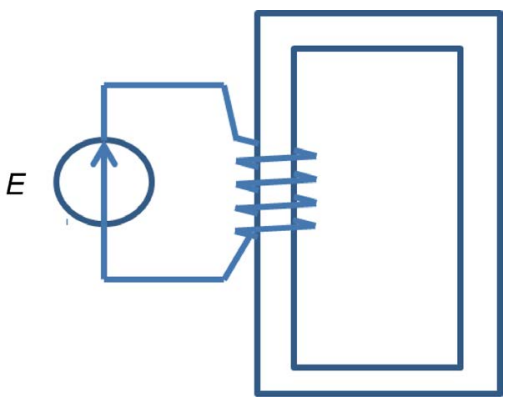

Figure 2. Single-phase ideal magnetic core magnetized with voltage source. 


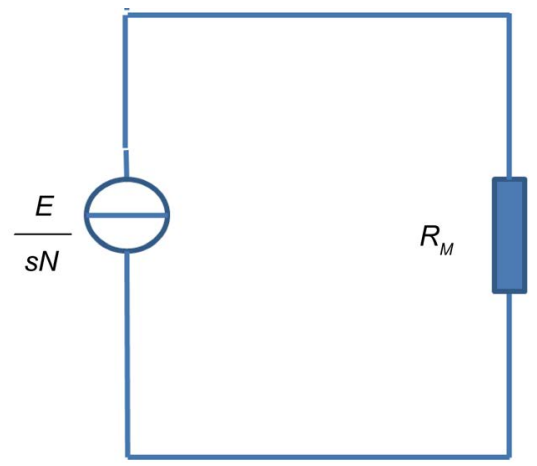

Figure 3. Magnetic equivalent of electric circuit in

Figure 2.

current $I$ is mapped to MMF of $N I$, when $N$ is the number of turns as shown in Figure 4.

Rule 3: Transformation of resistive load into inductance

Considering a transformer limb in which there is constant flux $(\phi)$ and winding in which there is a resistive load $R_{\mathrm{LOAD}}$ connected, there is a relationship between flux ( $\phi$ ) and current (I) as in (3) below.

$$
s N \phi=R_{\mathrm{LOAD}} I
$$

On the other hand, the magnetomotive force is $V_{m}=N I$. Combining this with (3) $V_{m}$ can be written as,

$$
V_{m}=\frac{s N^{2}}{R_{\mathrm{LOAD}}} \phi
$$

This described that resistive load connected to transformer windings can be represented as a reluctance given in (5). Considering the nature of the expression it can be seen, that a resistive load in electrical domain can be represented as an inductor in magnetic domain.

$$
R_{M}=\frac{s N^{2}}{R_{\mathrm{LOAD}}}
$$

\section{Rule 3: Transformation of inductive load into resistance}

When the impedance connected to the winding is an inductor, similar analysis (as described above) can be done to get that the reluctance presented is not frequency dependent as can be seen in Equation (6). Thus, it can be represented as a resistor in magnetic domain.

$$
R_{M}=\frac{N^{2}}{L}
$$

Rule 4: Transformation of capacitance into non-linear negative resistance

When the impedance in the winding is purely capacitive, the resulting reluctance becomes as described in (7). In frequency space the reluctance is negative, real and squarely dependent on frequency (8).

$$
\begin{gathered}
R_{M}=s^{2} N^{2} C \phi \\
R_{M}=-\omega^{2} N^{2} C \phi
\end{gathered}
$$



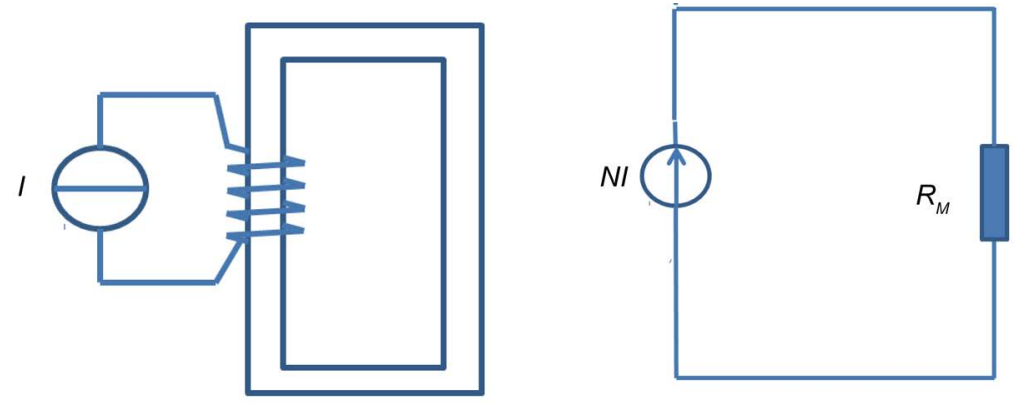

Figure 4. Current source in electrical domain and voltage source in magnetic domain.

\section{Rule 5: Transformation of complex impedance into complex reluctance}

When the impedance connected to the transformer contains both resistive and reactive parts, the reluctance has a complex value:

$$
\begin{aligned}
& R_{M}=\frac{j \omega N^{2}}{R+j X} \\
& R_{M}=\frac{-\omega N^{2} X+j \omega N^{2} R}{R^{2}+X^{2}}
\end{aligned}
$$

Rule 6: Transformation of Thevenin source into Thevenin or Norton source

Thevenin equivalent source is typically connected to transformer windings. This transforms a Thevenin source in magnetic domain. This can be calculated by first writing the induced voltage in the electrical circuit (11) and combining this with the definition of magnetomotive force (12).

$$
\begin{gathered}
E-Z I=s N \\
V_{M}=-N I
\end{gathered}
$$

Developing this further, an expression for the magnetomotive force is given as,

$$
V_{M}=-\frac{N E}{Z}+\frac{s N^{2} \phi}{Z}
$$

Therefore, a Thevenin source can be transformed to electrical domain as Thevenin or Norton source, depending which suits better for the analysis following. Thevenin source voltage is in (14) and Norton source current is in (16). The corresponding mappings are presented in Figure 5 and Figure 6.

$$
\begin{aligned}
V_{T} & =-\frac{N E}{Z} \\
R_{T} & =\frac{s N^{2}}{Z} \\
I_{N} & =\frac{E}{S N}
\end{aligned}
$$

Table 1 summarizes the analogies between electric lumped elements and their magnetic counterparts. 


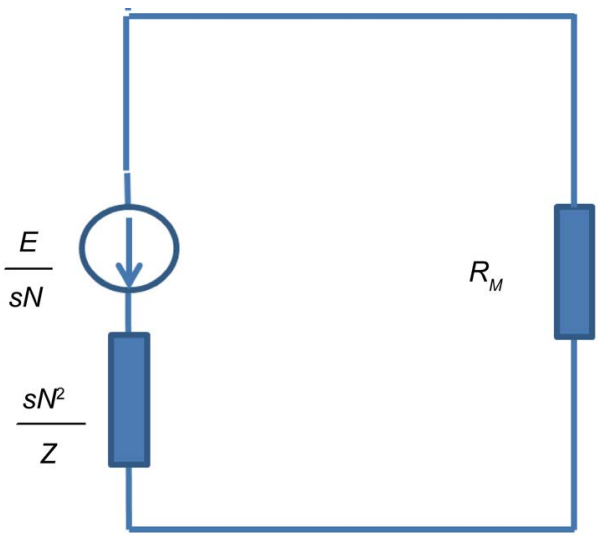

Figure 5. Thevenin electrical source mapped to Thevenin source in magnetic domain.

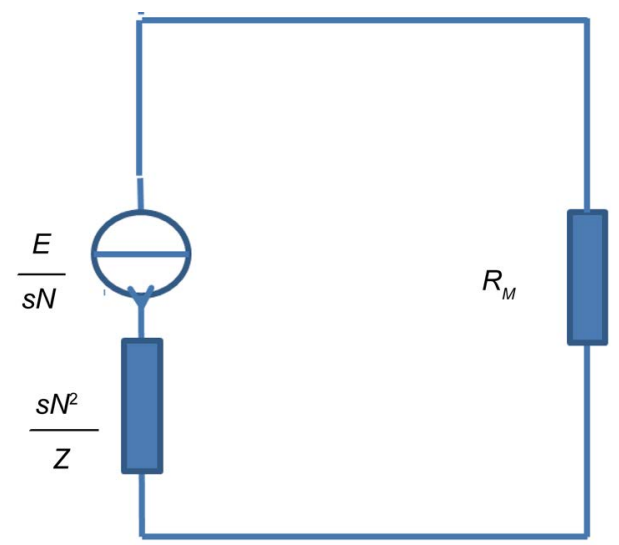

Figure 6. Thevenin electrical source mapped to Norton source in magnetic domain.

Table 1. Mapping of lumped electric elements to magnetic equivalents.

\begin{tabular}{cccc}
\hline $\begin{array}{c}\text { Electric lumped } \\
\text { element }\end{array}$ & Variable & $\begin{array}{c}\text { Mapped magnetic } \\
\text { element }\end{array}$ & $\begin{array}{c}\text { Transform in } \\
\text { Laplace space }\end{array}$ \\
\hline Voltage source & $E$ & Flux source & $\frac{E}{s N}$ \\
Current source & $I$ & Voltage source & $N I$ \\
Resistance & $R$ & Inductance & $\frac{s N^{2}}{R}$ \\
Inductance & $L$ & Resistance & $\frac{N^{2}}{L}$ \\
Capacitance & $C$ & $\begin{array}{c}\text { Negative impedance with } \\
\text { square frequency } \\
\text { dependency }\end{array}$ & $-s^{2} N^{2} C$ \\
& & Thevenin or Norton & Current: $\frac{E}{s N}$ \\
Thevenin source & & source with inductance & \\
& & & Impedance: $\frac{s N^{2}}{Z}$
\end{tabular}




\section{Non-Linear Magnetic Core}

The magnetic cores typically present non-linear flux-MMF relationships, which depend on the characteristics of the $\mathrm{B}(\mathrm{H})$ curves of the core material. This nonlinearity can be taken into account in this analysis by considering the reluctance elements as non-linear resistances. Using the mappings as described in the previous sections together with the non-linear magnetic core reluctances makes it possible to systematically construct system of non-linear differential equations describing the behavior of the electric-magnetic system. Symbol p marks the differentiation operator.

Referring to Figure 7(b) differential equation can be written (17) and, with the knowledge of the function it can be solved numerically. Function $V(\phi)$ gives the magnetomotive force as a function of flux and it can be derived from the $\mathrm{B}(\mathrm{H})$ curve of the magnetic core. In a case, where $V(\phi)$ is to be calculated for a limb with given length 1 and cross section A Equation (18) can be used, where $\mathrm{B}(\mathrm{H})$ gives the magnetic flux density as a function of the magnetic field in the core material. This can be derived assuming the magnetic of cross section $\mathrm{A}$ core to be a loop of length 1 without leakage flux. The magnetomotive force equals $\mathrm{I}^{\star} \mathrm{H}$ and flux is $\mathrm{B}{ }^{*} \mathrm{~A}$, where $\mathrm{B}$ is the magnetic flux density.

$$
-\frac{N_{P} E}{Z}=\frac{N_{P}^{2}}{R_{W}} \phi^{\prime}+\frac{N_{S}^{2}}{R_{L}} \phi^{\prime}+V(\phi)
$$

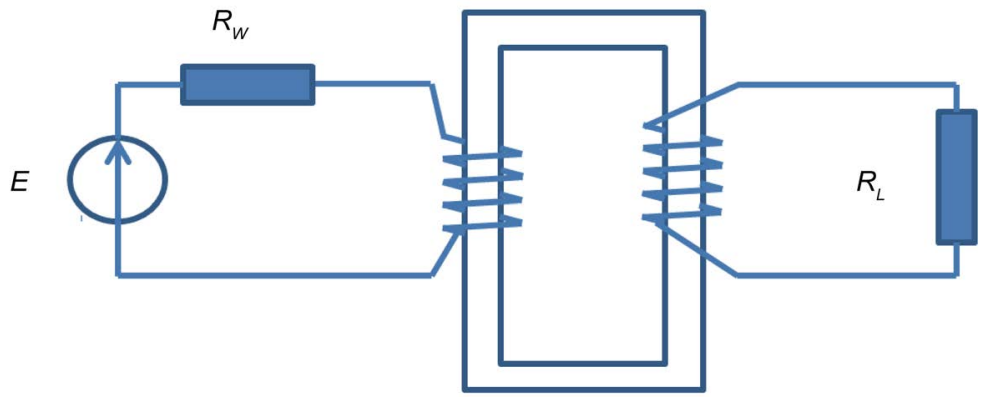

(a)

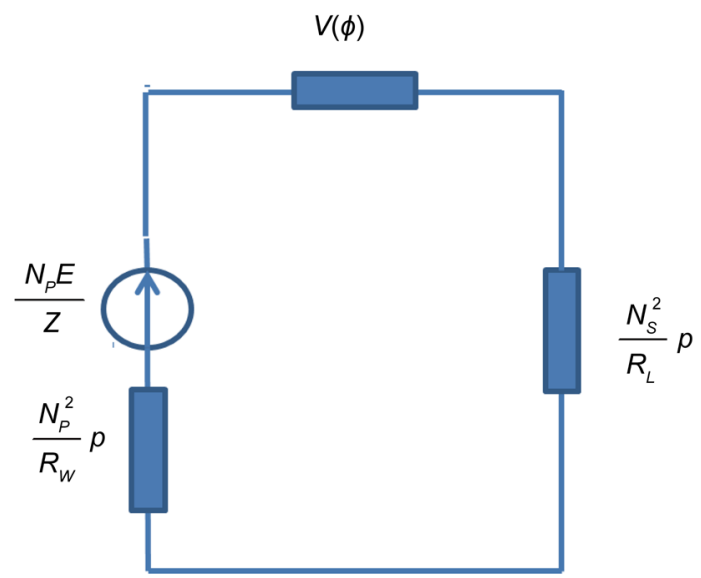

(b)

Figure 7. Analysis with non-linear magnetic core. 


$$
V(\phi)=l B^{-1}\left(\frac{\phi}{A}\right)
$$

\section{Analysis of Practical Transformer Structures Using Reluctance Methods}

Two cases are analyzed by using the proposed method. First one is a three-limb three-phase transformer with asymmetric core, leakage flux and winding resistances. Symmetry behavior of this transformer is studied using the proposed methods. Second one is a single-phase transformer with leakage reluctance and winding resistances and its performance is analyzed in transient and high load situations.

\subsection{Three-Limb Three-Phase Delta-Wye Connected Transformer with Asymmetries}

Referring to the transformer in Figure 8, the corresponding reluctance network is described as Figure 9. It includes the yoke reluctances, which create asymmetry and leakage reluctances for each limb. There is a winding resistance in both the primary and secondary side. The analysis is aimed to verify the following,

- The impact of reluctance asymmetry to the output voltage asymmetries in different symmetric load conditions

- The behavior of the voltages in the secondary, when the load is heavily asymmetric.

As discussed in section one, this kind of transformer with asymmetries in core is hard to analyze using traditional methods.

The proposed method is applied by first mapping the electrical circuits surrounding the coupled inductor. The three primaries are Thevenin sources and rule 6 is applied. The secondaries are resistive loads and rule 3 is applied.

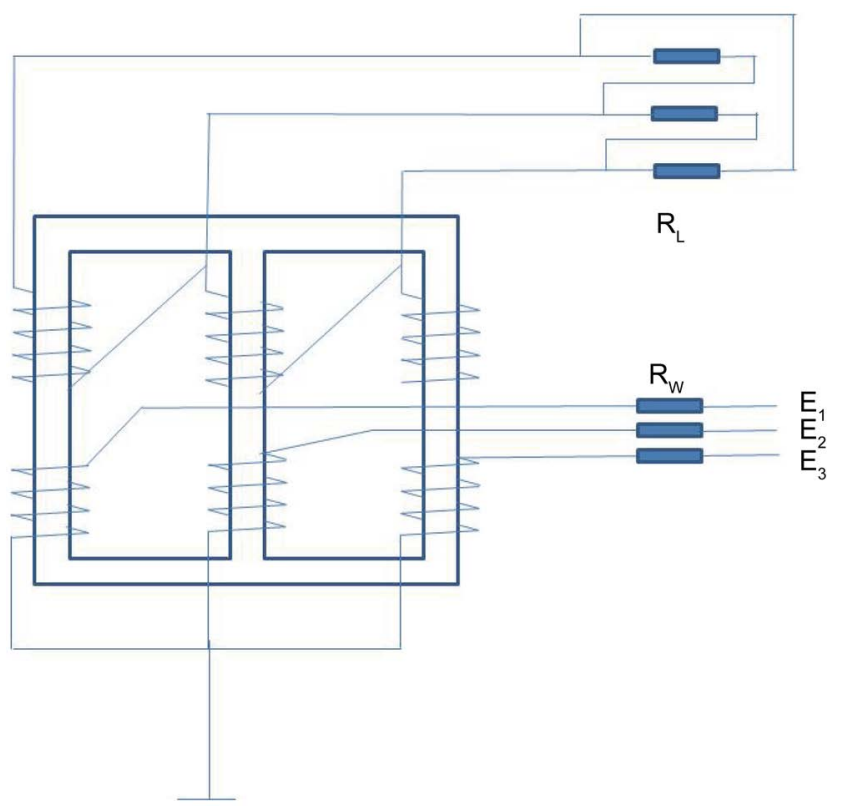

Figure 8. Three-phase wye-delta transformer. 


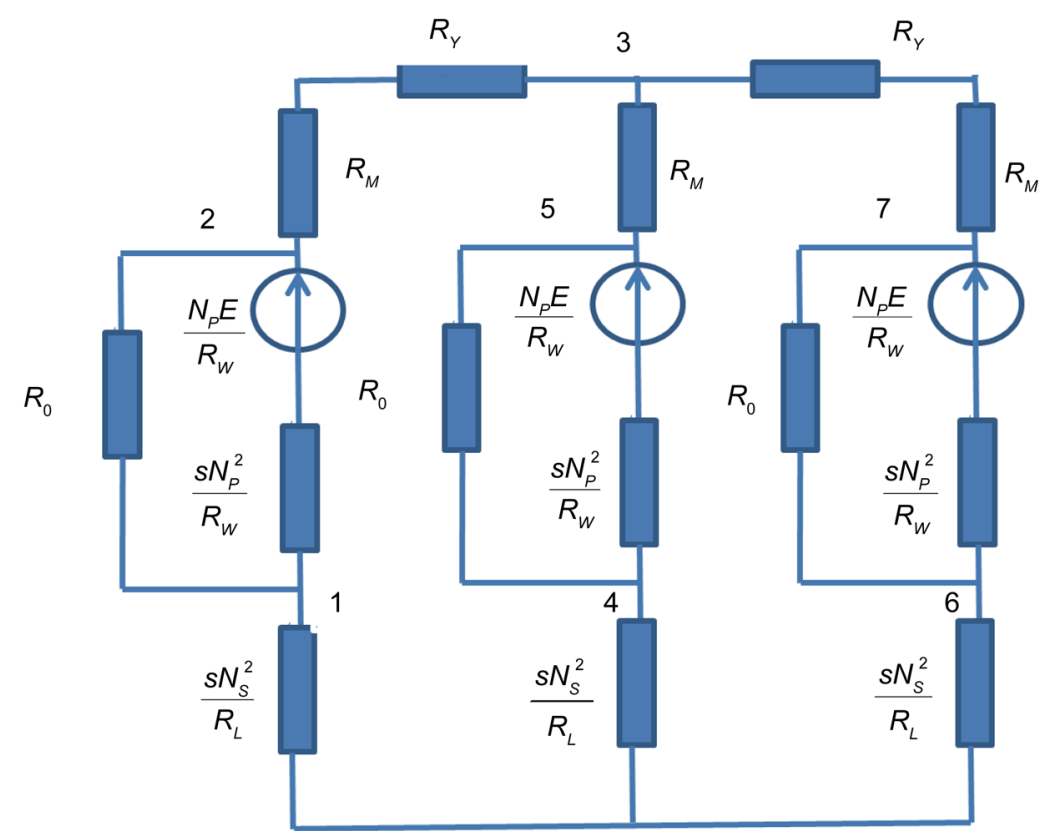

Figure 9. Reluctance network of transformer under study.

After applying the described rules the network to be solved is as shown in Figure 9. Using a Nodal analysis method [15] from circuit analysis the circuit is solved.

Impact of yoke reluctance asymmetry is studied by providing symmetrical voltage to the primary, symmetrical load at different levels and observing the negative sequence voltage in the secondary. Negative sequence output voltage as a function of load resistance is shown in Figure 10.

This analysis shows that the asymmetry created by yoke reluctances in the magnetic core do induce substantial asymmetries in the output voltages.

Second view is to look at, how the transformer performs, when primary voltages are symmetrical, but load is asymmetrical and resistive. Figure 11 shows the phase voltages in the secondary. It shows, that under asymmetrical load in the outer limb secondary means, that at higher loads the voltage in the center limb starts to increase over the nominal voltage. Figure 12 shows that the negative sequence voltages do not rise substantially, however.

\subsection{Single-Phase Transformer with Leakage Reluctance}

\subsubsection{Linear Magnetic Core}

Second case concerns single-phase transformer including leakage flux and winding resistances as in Figure 13. The core is linear (Figures 13-15).

\subsubsection{Non-Linear Magnetic core}

To demonstrate the capabilities of the proposed method the system shown in Figure 13 is analyzed, when the magnetic core is non-linear. The two limbs have $\mathrm{B}(\mathrm{H})$ characteristics of M-15 metal/11/described in Figure 16(a) and Figure 16(b). Assuming limb length of $250 \mathrm{~mm}$ and cross sectional area of $50 \mathrm{~mm} \times 50$ mm, non-linear function $V(\phi)$ can be derived, which maps the limb flux to 


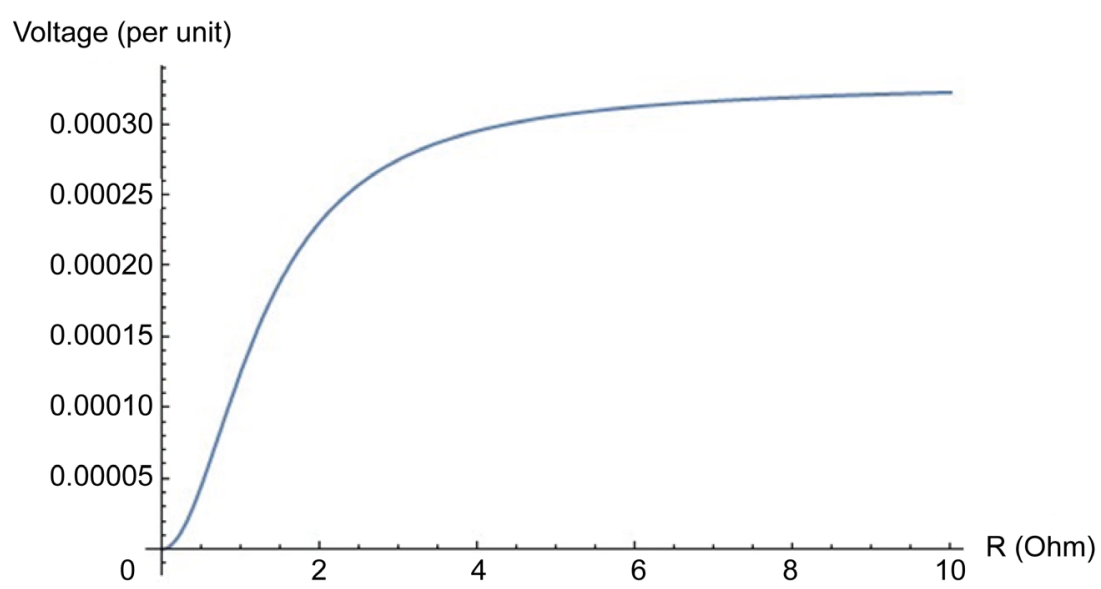

Figure 10. Negative sequence voltage (per unit) in the secondary.

Voltage (per unit)

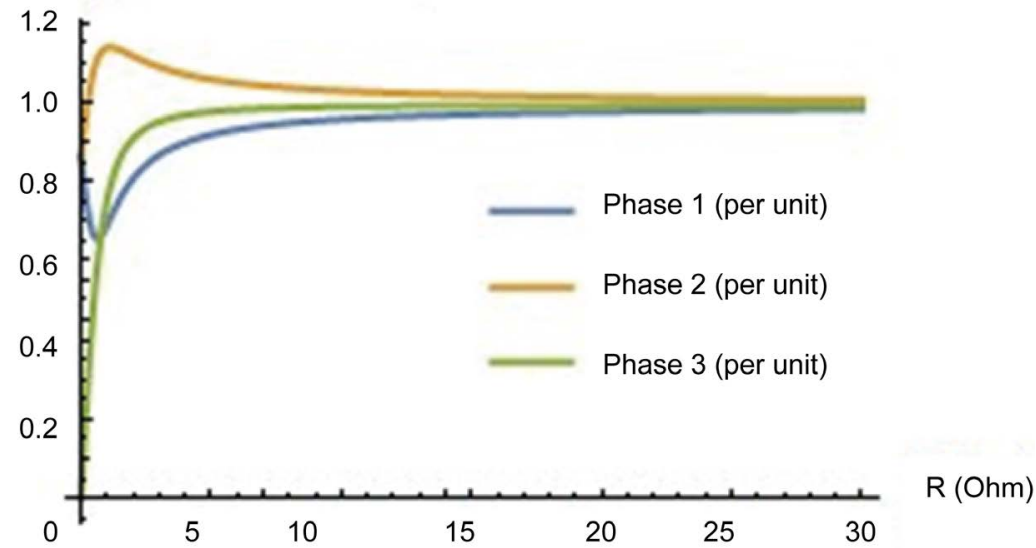

Figure 11. Phase voltages under asymmetrical resistive load.

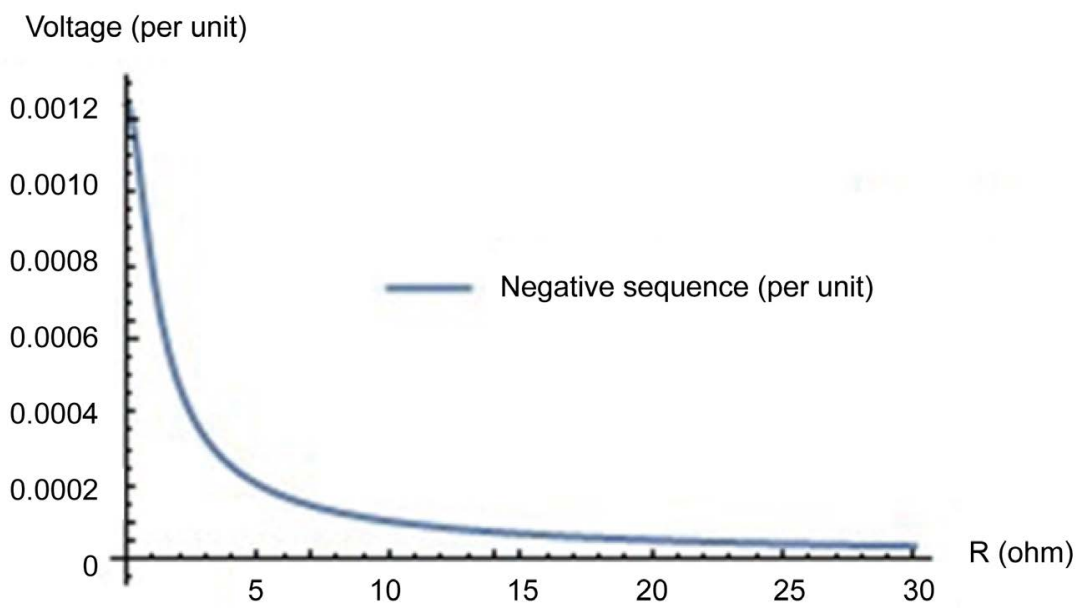

Figure 12. Negative sequence voltage (per unit).

magnetomotive force. This function is presented in Figure 17.

The differential equations derived using the methods in this paper are described in (19) and (20). 

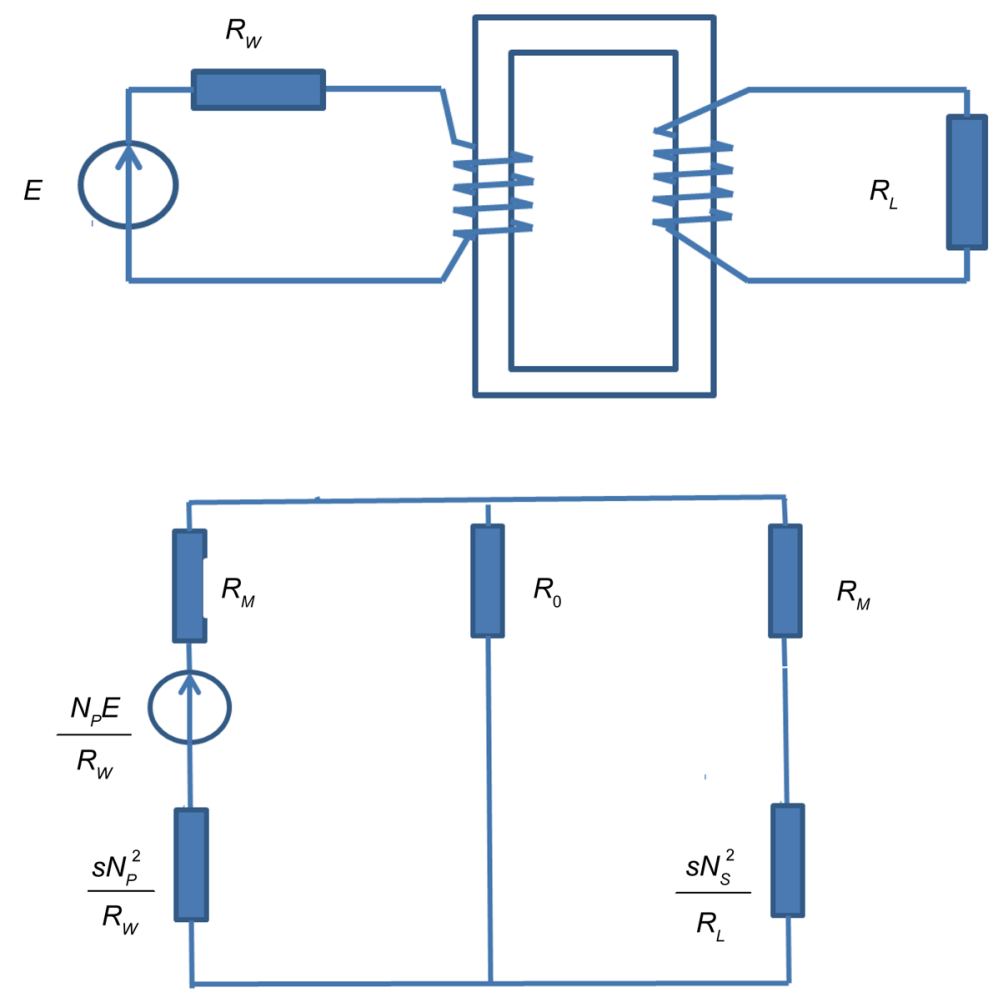

Figure 13. Single-phase transformer with leakage reluctance.

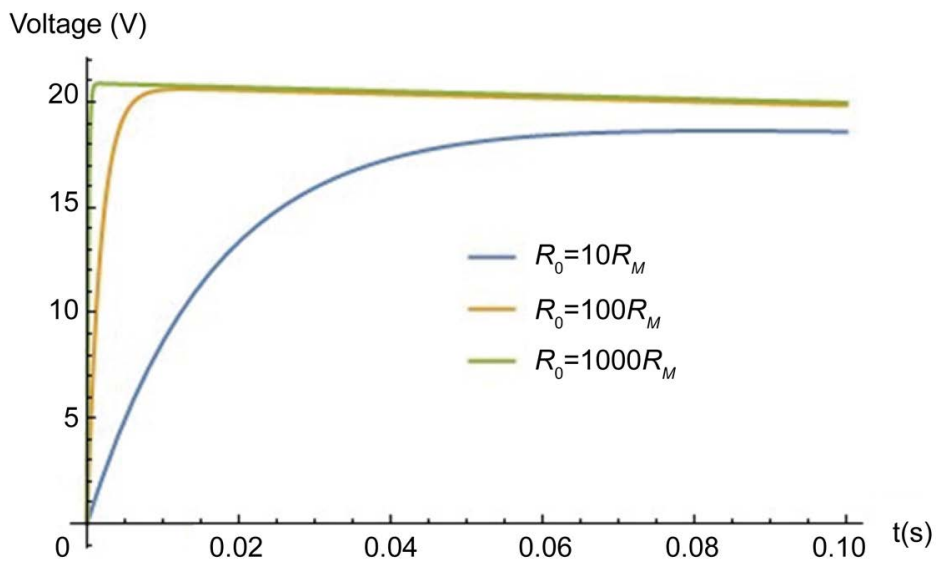

Figure 14. Secondary voltages as a function of load resistance for different leakage reluctances.

$$
\begin{aligned}
& \frac{N_{P}}{R_{W}} V_{P} \sin (\omega t)=\frac{N_{P}^{2}}{R_{W}} \phi_{1}^{\prime}[t]+V\left(\phi_{1}[t]\right)+R_{0}\left(\phi_{1}[t]-\phi_{2}[t]\right) \\
& 0=\frac{N_{S}^{2}}{R_{L}} \phi_{2}^{\prime}[t]+V\left(\phi_{2}[t]\right)+R_{0}\left(\phi_{2}[t]-\phi_{1}[t]\right)
\end{aligned}
$$

Solving these differential equations numerically in a case, where the load is 10 $\mathrm{Ohm}$ and primary winding resistance is $10 \mathrm{Ohm}$ and primary and secondary turns are 1000 and 100 respectively, gives fluxes as in Figure 18 and secondary voltages as in Figure 19. 


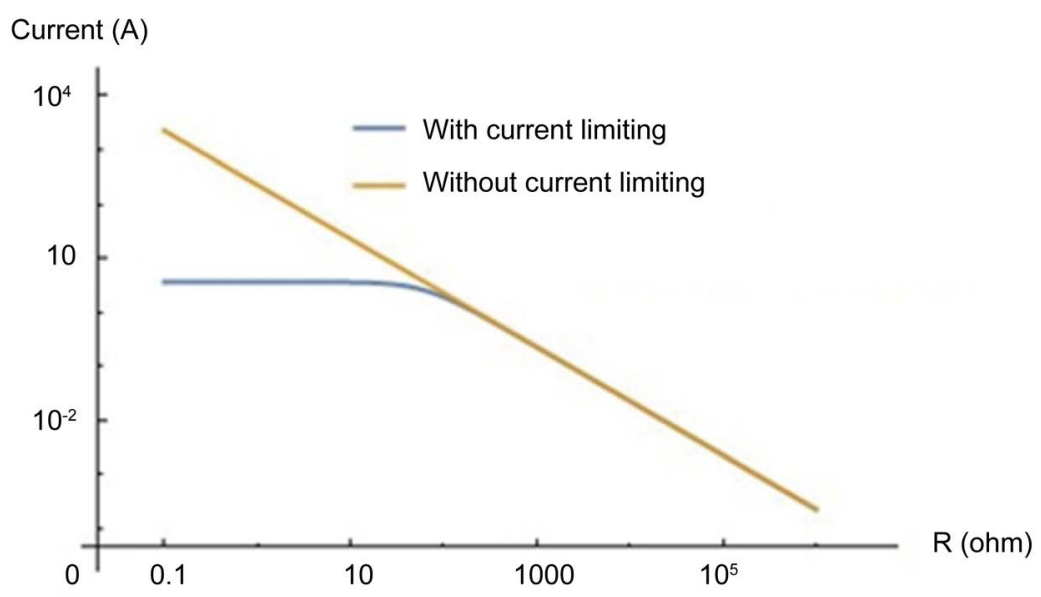

Figure 15. Current limiting function, short circuiting secondary.

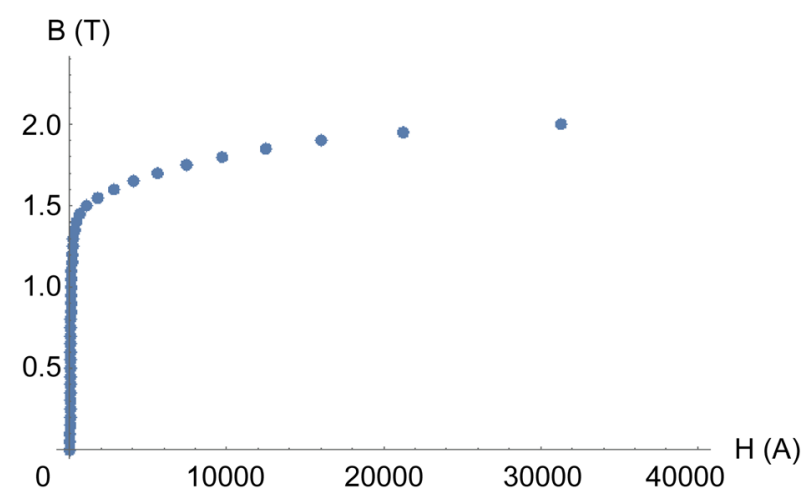

(a)

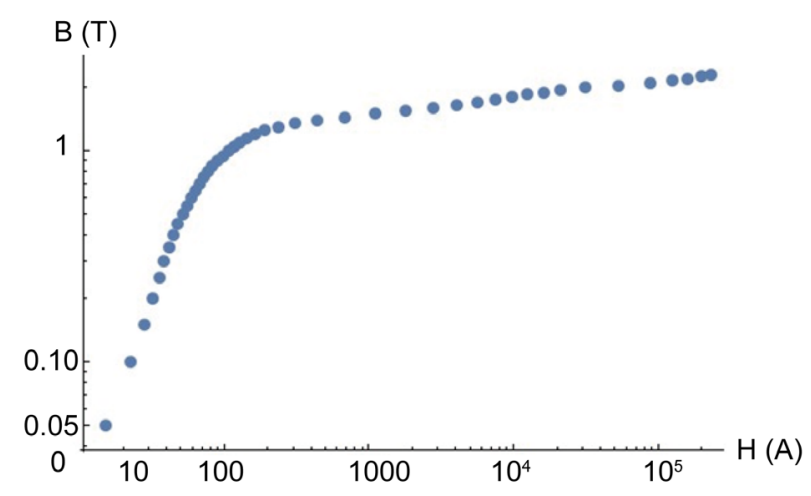

(b)

Figure 16. $\mathrm{B}(\mathrm{H})$ curve of electrical steel are shown as (a) linear scale, and (b) logarithmic scale.

\section{Conclusion}

A systematic method to analyze complex coupled inductors based on straight forward reluctance transformation rules is presented. This method facilitates the analysis of such transformer structures that could not be analyzed using the methods known in current transformer literature. In particular this applies to transformers, which have asymmetric reluctance network. The method makes it 


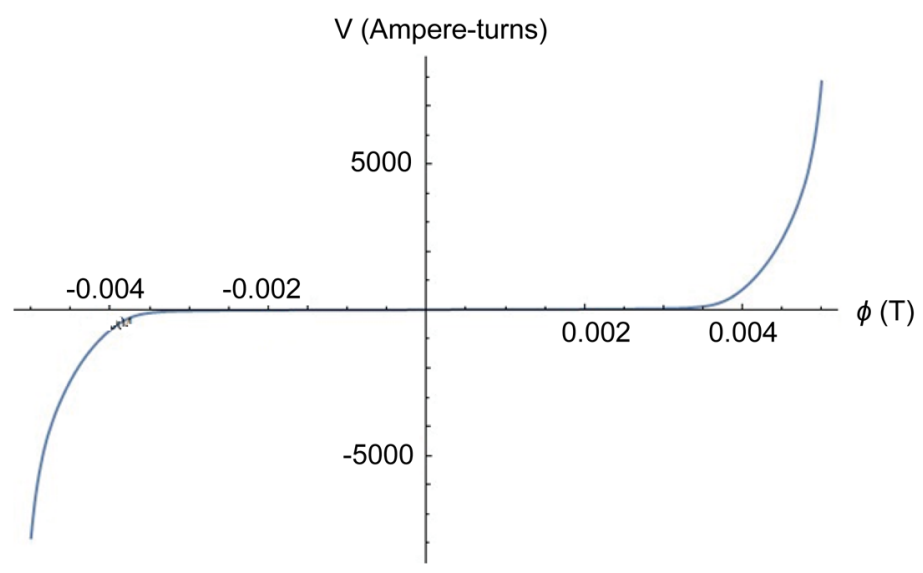

Figure 17. $V(\phi)$ curve of derived from $\mathrm{B}(\mathrm{H})$ curve.

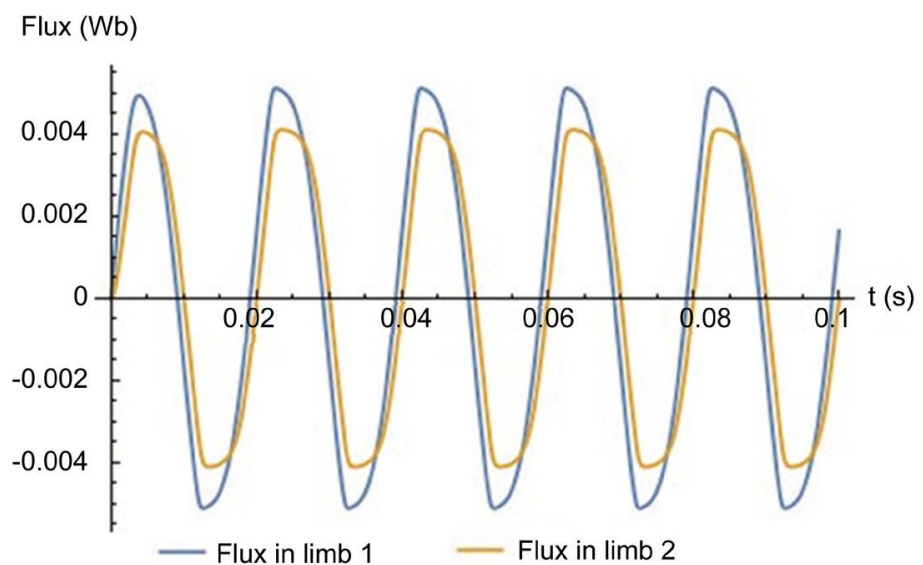

Figure 18. Fluxes in the limbs.

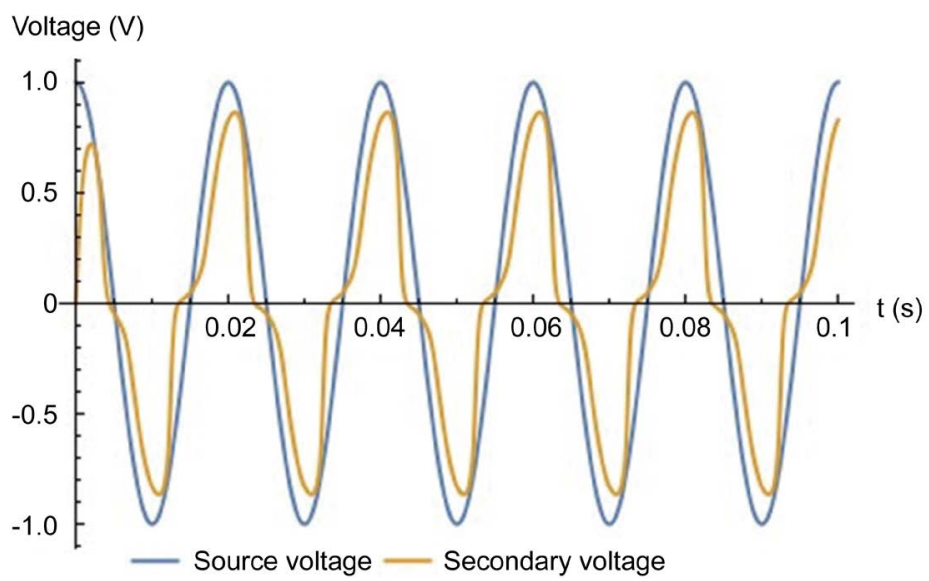

Figure 19. Source and secondary voltages.

possible also to systematically incorporate the dynamics of the surrounding electric circuits around the coupled inductor in a systematic manner.

\section{References}

[1] Saldafia, C. and Calzolari, G. (1997) Analysis of Core Type Transformer Models 
Based on the Principle of Duality in Electromagnetic Transients Studies. International Conference on Power Systems Transients (ISPT'97), Seattle, June 22-26, 87.

[2] Allmeling, J., Hammer, W. and Schönberger, J. (2012) Transient Simulation of Magnetic Circuits Using the Permeance-Capacitance Analogy. IEEE 13th Workshop on Control and Modeling of Power Electronics (COMPEL), Kyoto, Japan, 10-13 June 2012.

[3] Nogueira, A. and Maldonado, L. (2013) Analysis of Electromagnetic Devices Using the Principle of Duality between Electrical and Magnetic Circuits together with Finite Element Analysis. International Journal of Research and Reviews in Applied Sciences, 14, No. 3.

[4] Kulkarni, S. and Khaparde, S. (2012) Transformer Engineering. Second Edition, CRC Press, Boca Raton.

[5] Del Vecchio, R., Poulin, B., Feghali, P., Shah, D. and Ahuja, R. (2010) Transformer Design Principles. Second Edition, CRC Press, Boca Raton. https://doi.org/10.1201/EBK1439805824

[6] Brailsford, et al. (1954) Current and Power Relationship in the Measurement of Iron Losses in a Three-Limb Transformer Core.

[7] Corcoles, F., Sainz, L., Pedra, J., Sancez-Navarro, J. and Salichs, M. (2008) ThreePhase Transformer Modelling for Unlanbaced Conditions, Part I: Core Modeling and Introductory Examples. IET Electric Power Applications, 2, 99-112. https://doi.org/10.1049/iet-epa:20070290

[8] Chen, X.S. (1997) A Three-Phase Three Winding Core-type Transformer Model for Low-Frequency Transient Studies. IEEE Transactions on Power Delivery, 12, No. 2.

[9] teNyienhuis, E.G., Mechler, C.F. and Girgis, R.S. (2002) Flux Distribution and Core Loss Calculation for Single Phase and Five Limb Three Phase Transformer Core Designs. IEEE Transactions on Power Delivery, 15, No. 1.

[10] Escarela-Perez, R., Kulkarni, S.V., Kodela, N.K. and Olivares-Galvan, J.C. (2007) Asymmetry Diring Load-Loss Measurement of Three-Phase Three-Limb Transformers. IEEE Transactions on Power Delivery. http://ieeexplore.ieee.org/xpl/mostRecentIssue.jsp?punumber $=4275198$

[11] Dzafiq, I., Jabr, R.A. and Neisius, H.-T. (2015) Transformer Modeling for ThreePhase Distribution Network Analysis. IEEE Transactions on Power Systems, 30, No. 5.

[12] Chen, X.S. (1995) A Three-Phase Multi-Legged Transformer Model in ATP Using the Directly Formed Inverse Inductance Matrix. IEEE Transactions on Power Delivery, 11 , No. 3.

[13] Micro_Cap 11 (2014) Electronic Circuit Analysis Program User's Guide, Spectrum Software. Version 11, Spectrum Software.

[14] (2009) ATPDRAW, Version 5.6, for Windows 9x/NT/2000/XP/Vista, User's Manual.

[15] Sarma, S., Glover, J. and Overbye, T. (2012) Power System Analysis and Design. 5th Edition, Cengage Learning, Stamford. 
Submit or recommend next manuscript to SCIRP and we will provide best service for you:

Accepting pre-submission inquiries through Email, Facebook, LinkedIn, Twitter, etc. A wide selection of journals (inclusive of 9 subjects, more than 200 journals)

Providing 24-hour high-quality service

User-friendly online submission system

Fair and swift peer-review system

Efficient typesetting and proofreading procedure

Display of the result of downloads and visits, as well as the number of cited articles Maximum dissemination of your research work

Submit your manuscript at: http://papersubmission.scirp.org/

Or contact jpee@scirp.org 